\title{
An Investigation of Autonomous Vehicle Roundabout Situation
}

\author{
Hang CaO${ }^{1}$, Máté Zöldy ${ }^{\text {* }}$ \\ ${ }^{1}$ Department of Automotive Technologies, Faculty of Transportation Engineering and Vehicle Engineering, \\ Budapest University of Technology and Economics, 1111 Budapest, Stoczek J. u. 6., Hungary \\ * Corresponding author, e-mail: mate.zoldy@auto.bme.hu
}

Received: 21 January 2019, Accepted: 07 February 2019, Published online: 04 August 2019

\begin{abstract}
The aim of this paper is to evaluate the impact of connected autonomous behavior in real vehicles on vehicle fuel consumption and emission reductions. Authors provide a preliminary theoretical summary to assess the driving conditions of autonomous vehicles in roundabout, which attempts exploring the impact of driving behavior patterns on fuel consumption and emissions, and including other key factors of autonomous vehicles to reduce fuel consumption and emissions. After summarizing, driving behavior, effective in-vehicle systems, both roundabout physical parameters and vehicle type are all play an important role in energy using. ZalaZONE's roundabout is selected for preliminary test scenario establishment, which lays a design foundation for further in-depth testing.
\end{abstract}

Keywords

driving behavior, autonomous vehicle, fuel consumption and emission

\section{Introduction}

With the development of autonomous vehicle (AV) technology, current research are more inclined to focus on decision making made by vehicle, instead of human driver Mersky and Samaras (2016). Main reason in behind is the fact that reliability and reaction time of autonomous system are better than humans. It is stated that modern autonomous vehicles can sense their local environment, various objects they found are classified, can be explained by sensory information, to determine the appropriate navigation path, while respecting transportation rules (Bimbraw, 2015).

Since the establishment of a roundabout on a city road, significant changes have been made in various aspects, such as the size, quality, traffic efficiency and management style of the roundabout. At the end of the twentieth century, modern roundabouts were widely used in Europe and the United States (Dabbour and Easa, 2006). These intersections have the advantages of priority in the roundabout, lower driving speed, smaller radius around the island, and counterclockwise travel around the island. Entrances and exits are normally four pairs and use the tangent line in the roundabout which is perpendicular roads. Wardrop (1957) believes that the capacity of the roundabout depends mainly on the length of the weaving area, and the length of the weaving area is directly proportional to the capacity of the traffic, and traffic rules for priority traffic are established, but this rule often leads to the roundabout. The occurrence of the deadlock phenomenon, therefore, the relevant scholars proposed the rules for entering the roundabout.

Turner and Roozenburg (2009) argue that deceleration is an advantage for a well-designed roundabout, which usually results in similar driving behavior. St-Aubin et al. (2013) proposed that when the roundabout provides multiple access roads and even increases the capacity of the short-distance lanes to increase the lane capacity, the vehicle's speed and driving behavior constraints will be reduced. Silva et al. (2006) studied the roundabout of different lane numbers and found that: by increasing the number of lanes, the roundabout can improve its traffic capacity to a certain extent, and the driver will have more driving space, but this will also lead to an increase in potential conflicts.

\section{Effective in-vehicle system and CAV on fuel consumption and emission}

Autonomous vehicles have the potential to improve link and roundabout traffic behavior. Connected autonomous vehicle (CAV) is much available to get information and communicate real-time data and cooperate with other road users. Evidence from current research indicates that in-vehicle systems have a positive impact on fuel consumption 
and can improve fuel efficiency. In-vehicle feedback systems are a new method that driver behavior changing has a positive impact on improving fuel efficiency (Joshué et al., 2011). There are many vehicle devices are designed to be used to improve fuel efficiency, for example dashboard displays, heads up displays and so on.

Barth and Boriboonsomsin (2009) found that fuel consumption can reduced about $10-20 \%$ by speed feedback via in-vehicle dashboard displays depending on the driving scene background. Similarly, when the bus driver gets real-time driving feedback through the vehicle-mounted eco-driving system, the fuel consumption of the bus is reduced by $6.8 \%$ (Strömberg and Karlsson, 2013). Horberry et al. (2014) summarized in-vehicle feedback systems classification with informing, warning and intervening (Vaezipour et al., 2015). Ardalan and Antonio (2018) claimed that potential impact of CAV on energy use could be multifaceted and not all active role in energy reduction. Fig. 1 is the summary of the main impact factors on energy using.

Even in complex traffic conditions that involve other traditional vehicles, energy-efficient automated vehicles still make contribution to fuel consumption reduction of surrounding traffic (Joshué et al., 2011; Antonya et al., 2015).

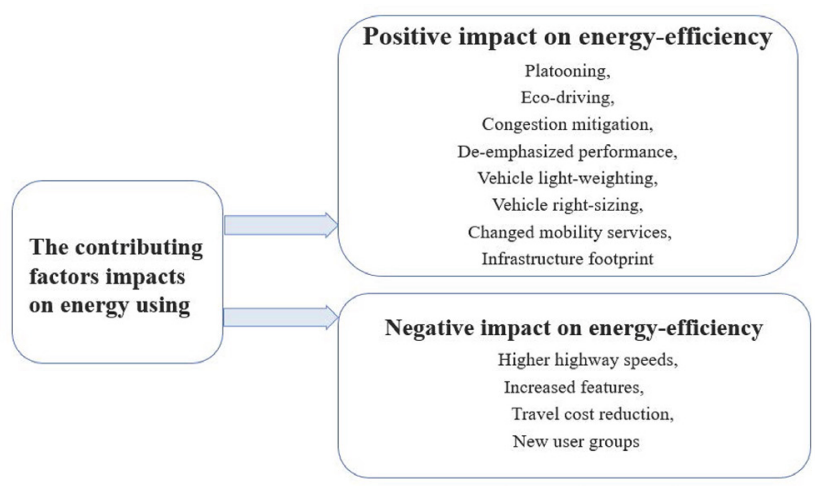

Fig. 1 The summary of the contributing factors influencing energy using (Joshué et al., 2011)

\section{Relationship between driving patterns and fuel efficiency}

Improving driving patterns and driving behavior has proven to drive an important role in energy efficiency and vehicle fuel consumption and emissions. Avoiding unnecessary stopping and achieve continuous speed, shifting to higher gears, using positive smooth acceleration, smooth deceleration instead of sharp braking etc. such driving pattern training for reducing vehicle energy consumption and emission is important (Vaezipour et al., 2015). Fig. 2 is the control system for autonomous vehicles crossing roundabouts.

Vaezipour et al. (2015) and Zöldy and Zsombók (2018) summarized energy efficiency influencing factors and their driving parameters safety aspects which highly dependent on the traffic surroundings, as shown in Fig. 3.

\section{Other factors affect fuel consumption and emission}

Another reason leading to increased vehicle emissions is the traditional roundabout traffic congestion. Vehicles at smart roundabouts reduce fuel consumption and have a positive impact on environmental protection compared to traditional roundabouts. Alkhaledi et al. (2015) compared speeds changing phase in both traditional roundabouts and smart roundabouts, as shown in Fig. 4.

Excessive idle time on busy intersections and long-period paths lead to increased fuel consumption and emissions at traditional roundabouts, while minimum delay and idle time can be achieved at smart roundabouts, resulting in lower fuel emissions. Both Fig. 5 and Fig. 6 show the speed profile which is determined by the characteristics of the right turn and the turn lane of the smart roundabout.

Vehicle type is also a factor to reduce fuel consumption and emission. Ardalan and Antonio (2018) has mentioned increase vehicle miles travel miles or reduce vehicle weight can get more chances for vehicle less fuel consumption and emission with CAVs.

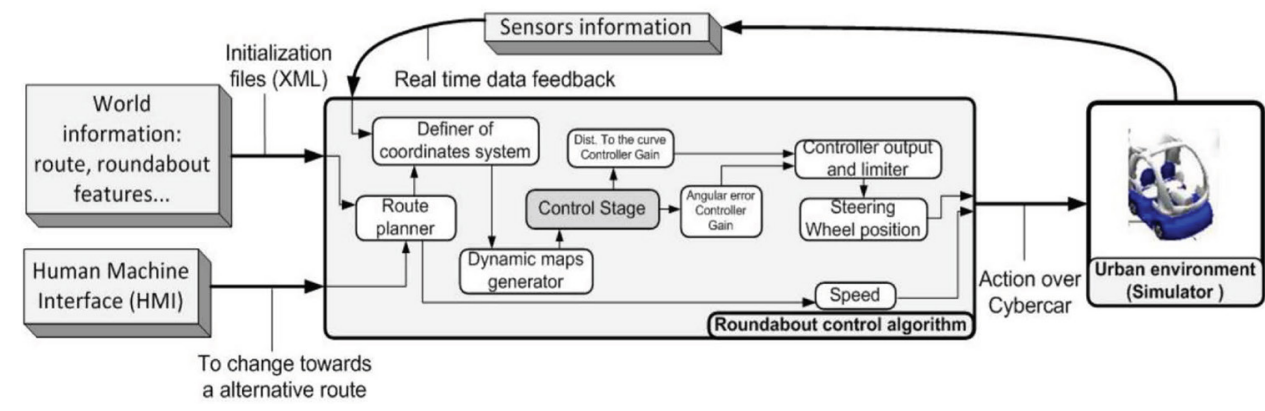

Fig. 2 Control system for autonomous vehicles crossing roundabouts (Joshué et al., 2011) 


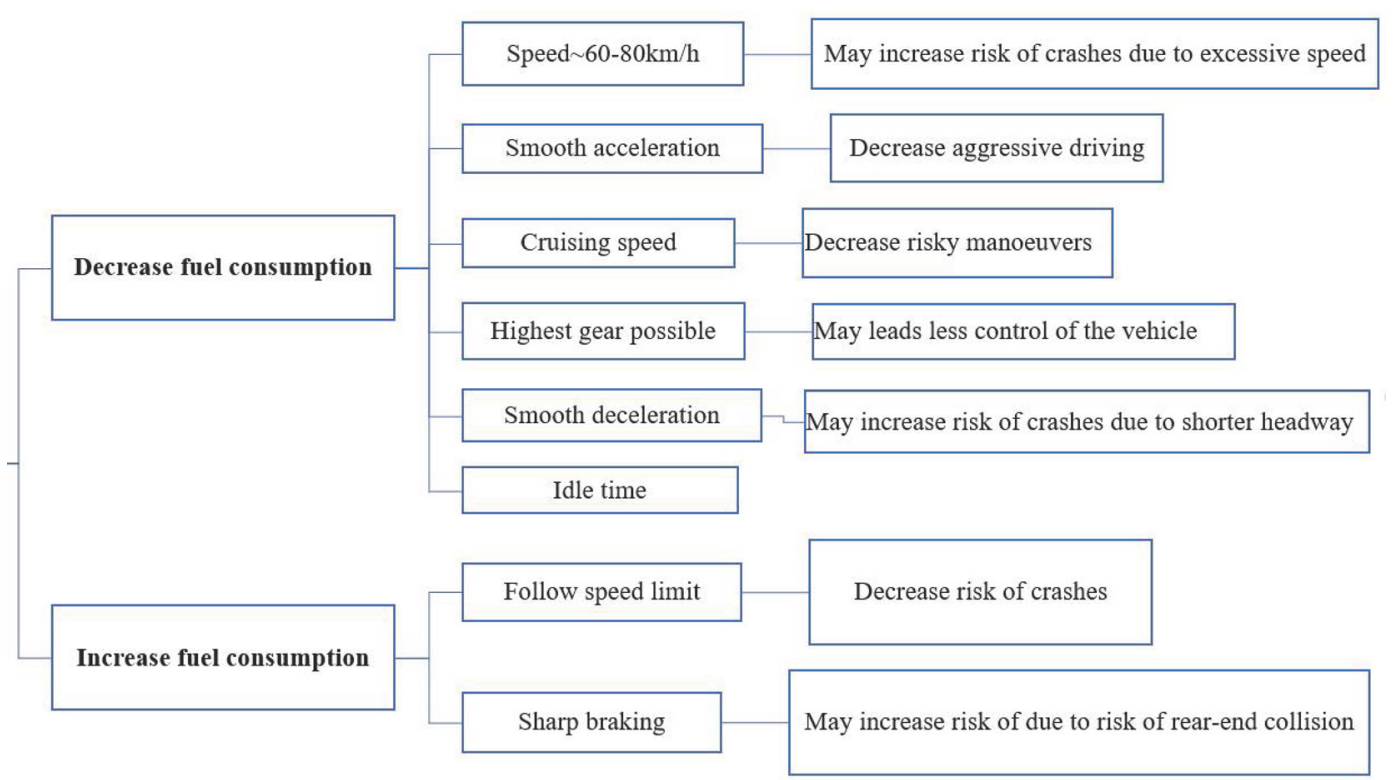

Fig. 3 Driving parameters impact on fuel consumption and safety (Vaezipour et al., 2015)

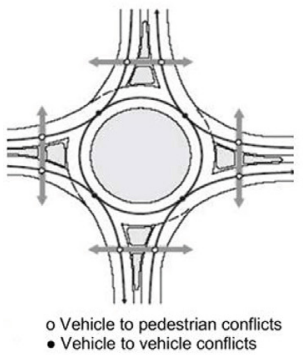

(a)

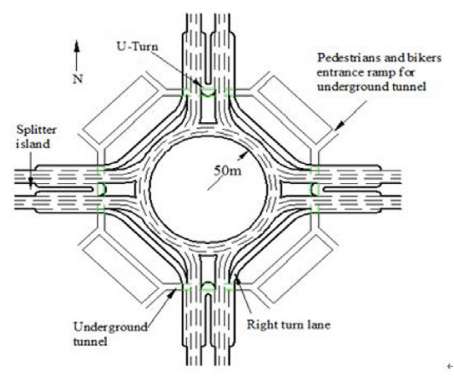

(b)
Fig. 4 (a) Traditional roundabout (b) Improved smart roundabout layout (Akcelik and Besely, 2002)

\section{Testing experiments and simulations}

However, there is no direct principle to evaluate the impact of AV technology on energy efficiency for current fuel economy testing methods. Electric vehicles and plug-in hybrids testing standards has been set by EPA which is different with traditional vehicle (Zöldy, 2018). In this case, manufacturers and markets cannot have a consistent fuel consumption and emission ratings to show fuel efficiency of their production. Therefore, companies are likely to reach the fuel efficiency through decision making control.

Driving cycle represents vehicle's performance including fuel consumption and emission parts, using data points. With autonomous vehicle technology is more and more popular, there exits drive cycles for autonomous and partially autonomous vehicles. Several vehicle fuel consumption test methods was listed (Zöldy, 2018), this paper

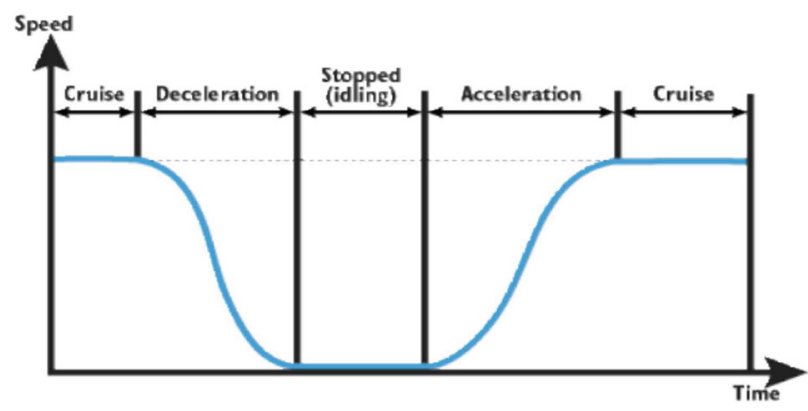

Fig. 5 The speed changing phase at general signalized intersection (Akcelik and Besely, 2002)

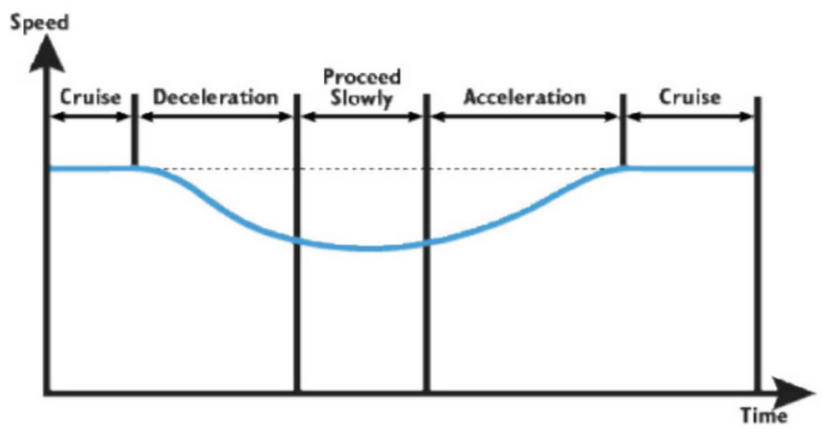

Fig. 6 The speed changing phase at the smart roundabout (Akcelik and Besely, 2002)

demonstrates a method for driving cycles incorporated into existing EPA test program will automatically follow.

"Vehicle Specific Power" (VSP) is the term describe mechanical engine load used for vehicle motion that has been shown to be highly related with vehicle emissions. Frey et al. (2002) exploited a "modal grading method" for 
computing VSP vehicle emissions based on speed, acceleration etc. requirements (Salamati et al., 2013).

In the supposed partial automation case, if the recommendations had been followed perfectly, what would have happened would be shown by a speed profile (Wu et al., 2014). According to the survey, partial automated vehicles save about 5-7\% of energy compared to human-driven vehicles.). Ardalan and Antonio (2015) summarized CAV optimize fuel efficiency mainly depend on envisage road conditions, signal characteristic and car following patterns. Vehicle information signal transmission technology is mainly Dedicated Short Range Communication (DSRC) or cellular communication SPaT is associated with traffic control center.

\section{Test scenario descriptions}

ZalaZONE is a special designed proving ground for automotive vehicles (Szalay et al., 2017) and the chosen roundabout is a standard single lane roundabout, $32.5 \mathrm{~m}$ in diameter. It has four legs and each adjacent leg angle is assumed as 90 degrees.

It is supposed that the crosswalk and the separator island appear at all entrances and exits, and that the length between the line and the yield is 5.5 meters, which can accommodate passengers. Fig. 7 is the screenshot of Prescan scenario editor and Table 1 is the main parameters of ZalaZONE roundabout dimensions.

The selected vehicle decelerates as it enters the roundabout, as shown in Fig. 8 and Fig. 9, designing the SMART to merge the BMW vehicle from the entrance ramp. In order to reduce the interference to the flow, it can only be merged into the gap between the rows, observe the difference between the different merged positions and the speed of the vehicle, then compare different scenarios. Table 2 is the summary of vehicle dimensions.
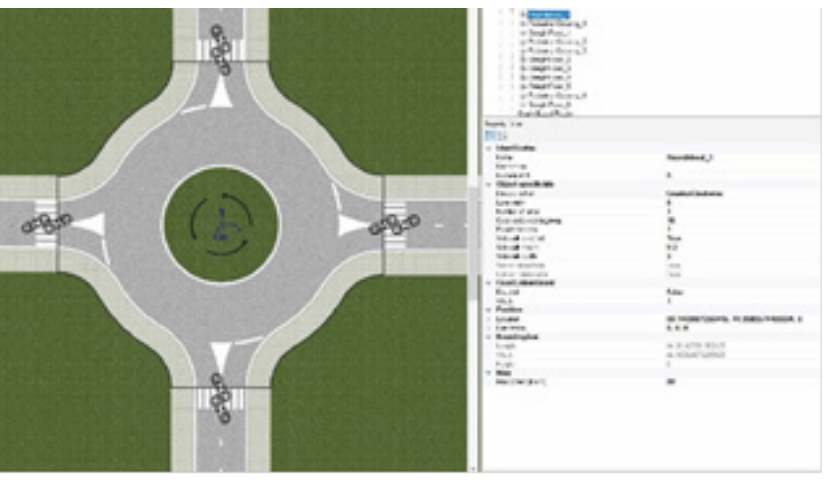

Fig. 7 ZalaZONE roundabout layout

\section{Conclusions}

The paper summarizes the impact of autonomous vehicle driving behavior on fuel conditions based on roundabout environment. Taking into account the above situation, as a conclusion, it should be emphasized that reducing energy

Table 1 ZalaZONE roundabout dimensions

\begin{tabular}{lc}
\hline ZalaZONE roundabout & Parameters $(\mathrm{m})$ \\
\hline Inscribed circle diameter & 32.5 \\
Entrance width & 3.61 \\
Exit width & 3.61 \\
Approach width & 3.25 \\
Departure width & 3.25 \\
Circulating roadway width & 7.58 \\
Apron & 1.80 \\
\hline
\end{tabular}

\begin{tabular}{lcc}
\hline & Table 2 Vehicle dimensions \\
\hline Configuration & BMW-X5-SUV & SMART \\
\hline Length (m) & 4.78 & 2.5 \\
Width (m) & 2.17 & 1.515 \\
Height (m) & 1.72 & 1.529 \\
Mass (kg) & 2220 & 805 \\
\hline
\end{tabular}

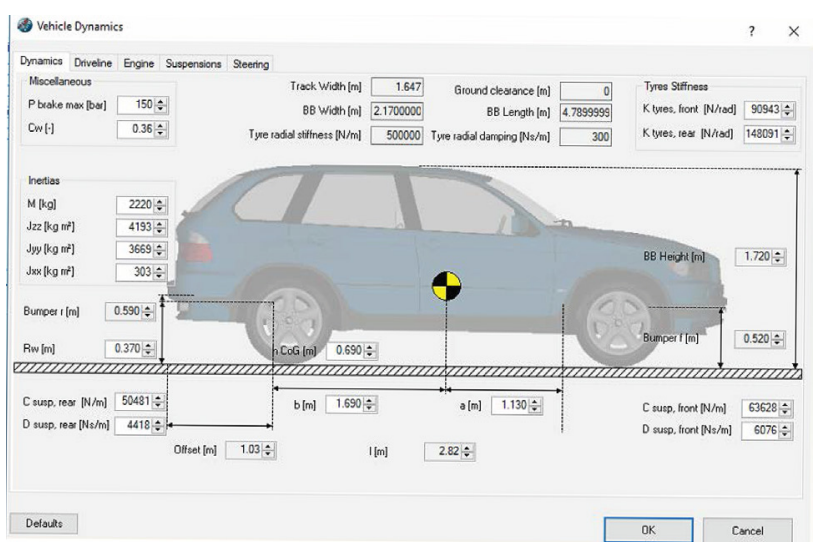

Fig. 8 BMW-X5-SUV configurations

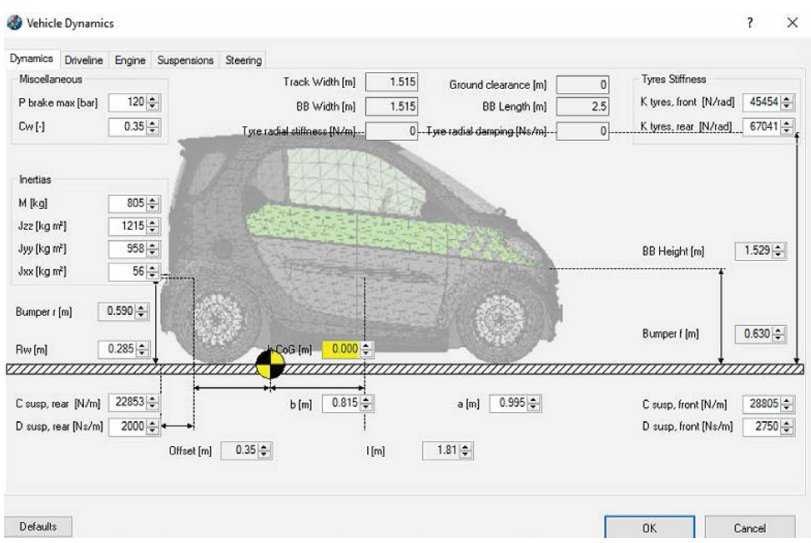

Fig. 9 SMART configurations 
consumption and emission at the roundabout should avoid sudden change in the road or traffic conditions and achieve smooth acceleration or deceleration.

After selecting the roundabout as test site and the vehicle types, the next step is to develop and build scenario models with different simulation environments, analyze and verify the driving behavior pattern of the autonomous vehicle in combination with the system architecture.

\section{References}

Akcelik, R., Besley, M. (2002) "SIDRA 6.0 User Guide", Akcelik \& Associates, ARRB Transport Research Ltd., Melbourne, Australia. [online] Available at: https://rid.trb.org/view/1192648 [Accessed: 20 January 2019]

Antonya, C., Butnariu, S., Beles, H. (2015) "Parameter Estimation from Motion Tracking Data", In: Duffy, V. G. (ed.) Digital Human Modeling. Applications in Health, Safety, Ergonomics and Risk Management: Ergonomics and Health, Springer, Cham, Switzerland. https://doi.org/10.1007/978-3-319-21070-4_12

Vahidi, A., Sciarretta, A. (2018) "Energy saving potentials of connected and automated vehicles", Transportation Research Part C: Emerging Technologies, 95, pp. 822-843. https://doi.org/10.1016/j.trc.2018.09.001

Barth, M., Boriboonsomsin, K. (2009) "Energy and emissions impacts of a freeway-based dynamic eco-driving system", Transportation Research Part D: Transport and Environment, 14(6), pp. 400-410. https://doi.org/10.1016/j.trd.2009.01.004

Bimbraw, K. (2015) "Autonomous Cars: Past, Present and Future A Review of the Developments in the Last Century, the Present Scenario and the Expected Future of Autonomous Vehicle Technology". In: Proceedings of the 12th International Conference on Informatics in Control, Automation and Robotics - Volume 1: ICINCO, Colmar, France, pp. 191-198. https://doi.org/10.5220/0005540501910198

Dabbour, E., Easa, S. (2006) "Proposed Geometric Features to Improve Safety of Modern Roundabouts", presented at Transportation Research Board 85th Annual Meeting, Washington, DC, USA, Jan. 22-26, 2006.

Frey, H. C., Unal, A., Chen, J., Li, S. (2002) "Evaluation and Recommendation of a Modal Method for Modeling Vehicle Emissions", presented at International Emission Inventory Conference "Emission Inventories - Applying New Technologies", Sab Diego, CA, USA, Apr. 28-May 1, 2003. [online] Available at: https://www3.epa.gov/ttnchie1/conference/ei12/mobile/frey.pdf [Accessed: 20 January 2019]

Pérez, J., Milanés, V., de Pedro, T., Vlacic, L. (2011) "Autonomous driving manoeuvres in urban road traffic environment: a study on roundabouts", IFAC Proceedings Volumes, 44(1), pp. 13795-13800. https://doi.org/10.3182/20110828-6-IT-1002.00423

Mersky, A. C., Samaras, C. (2016) "Fuel economy testing of autonomous vehicles", Transportation Research Part C: Emerging Technologies, 65, pp. 31-48. https://doi.org/10.1016/j.trc.2016.01.001

\section{Acknowledgement}

The research reported in this paper was supported by the Higher Education Excellence Program of the Ministry of Human Capacities in the frame of Artificial Intelligence research area of Budapest University of Technology and Economics (BME FIKP-MI/FM).

Salamati, K., Coelho, M. C., Fernandes, P. J., Rouphail, N. M., Frey, H. C., Bandeira, J. (2013) "Emissions Estimation at Multilane Roundabouts: Effects of Movement and Approach Lane", Transportation Research Record: Journal of the Transportation Research Board, 2389(1), pp. 12-21.

https://doi.org/10.3141/2389-02

Silva, A. B, Seco, A. J. M., da Silva, J. P. C. (2006) "Characterization of trajectories adopted at roundabout crossings", presented at European Transport Conference (ETC), Strasbourg, France, Sep. 18-20, 2006.

St-Aubin, P., Saunier, N., Miranda-Moreno, L. F., Ismail, K. (2013) "Use of Computer Vision Data for Detailed Driver Behavior Analysis and Trajectory Interpretation at Roundabouts", Transportation Research Record: Journal of the Transportation Research Board, 2389(1), pp. 65-77.

https://doi.org/10.3141/2389-07

Strömberg, H. K., Karlsson, M. A. (2013) "Comparative effects of eco-driving initiatives aimed at urban bus drivers - Results from a field trial", Transportation Research Part D: Transport and Environment, 22, pp. 28-33. https://doi.org/10.1016/j.trd.2013.02.011

Szalay, Zs., Tettamanti, T., Esztergár-Kiss, D., Varga, I., Bartolini, C. (2018), "Development of a Test Track for Driverless Cars: Vehicle Design, Track Configuration, and Liability Considerations", Periodica Polytechnica Transportation Engineering, 46(1), pp. 29-35. https://doi.org/10.3311/PPtr.10753

Torok, A., Torok, A., Heinitz, F. (2014) "Usage of Production Functions in the Comparative Analysis of Transport Related Fuel Consumption", Transport and Telecommunication, 15(4), pp. 292-298. https://doi.org/10.2478/ttj-2014-0025

Turner, S. A., Roozenburg, A. P., Smith, A. W. (2009) "Roundabout crash prediction models", New Zealand Transport Agency Research Report, New Zealand Transport Agency, Wellington, New Zealand, Rep. 386. [online] Available at: https://trid.trb.org/ view/914540 [Accessed: 20 January 2019]

Vaezipour, A., Rakotonirainy, A., Haworth, N. (2015) "Reviewing In-vehicle Systems to Improve Fuel Efficiency and Road Safety", Procedia Manufacturing, 3, pp. 3192-3199. https://doi.org/10.1016/j.promfg.2015.07.869

Wan, N., Vahidi, A., Luckow, A. (2016) "Optimal speed advisory for connected vehicles in arterial roads and the impact on mixed traffic". Transportation Research Part C: Emerging Technologies, 69 , pp. 548-563. https://doi.org/10.1016/j.trc.2016.01.011 
Wardrop, J. G. (1957) "The Traffic Capacity of Weaving Sections of Roundabouts", In: Proceedings of the First International Conference on Operational Research, Operations research Society of America, Baltimore, MD, USA.

Wu, G., Boriboonsomsin, K., Xia, H., Barth, M. (2014) "Supplementary Benefits from Partial Vehicle Automation in an Ecoapproach and Departure Application at Signalized Intersections", Transportation Research Record: Journal of the Transportation Research Board, 2424(1), pp. 66-75.

https://doi.org/10.3141/2424-08
Zöldy, M, Zsombók, I. (2018) "Modelling fuel consumption and refuelling of autonomous vehicles", MATEC Web Conferences, 235, Article ID: 00037. https://oi.org/10.1051/matecconf/201823500037

Zöldy, M. (2018) "Legal Barriers of Utilization of Autonomous Vehicles as Part of Green Mobility", In: Proceedings of the 4th International Congress of Automotive and Transport Engineering (AMMA 2018), Cluj-Napoca, Romania, pp. 243-248. https://doi.org/10.1007/978-3-319-94409-8_29 